\section{Glycosylated fetal haemoglobin}

Glycaemic control in the last trimester of pregnancy may be assessed by measuring the amount of glycosylated haemoglobin $\left(\mathrm{HbA}_{1 \mathrm{c}}\right)$ in maternal blood. This has been shown to be related to the neonatal skinfold thickness, which currently appears to be the best method for determining the impact of diabetic control during pregnancy on the fetus. ${ }^{1}$ A more direct way of assessing fetal glucose concentrations during late pregnancy might be to measure glycosylated haemoglobin in fetal blood. The stepwise-elution ion-exchange methods usually used do not, however, differentiate between glycosylated adult haemoglobin ( $\mathrm{HbA}$ ) and fetal haemoglobin $(\mathrm{HbF})$. We have used an isoelectric focusing (IEF) method to investigate the relation between the glycosylated haemoglobin fractions of the mothers and their babies.

\section{Subjects, methods, and results}

Maternal venous and fetal cord blood samples were obtained simultaneously from 10 insulin-treated and 14 non-diabetic mothers and their babies immediately after delivery. All blood samples were diluted with saline $(1: 10 \mathrm{v} / \mathrm{v})$ and were kept at $4 \mathrm{C}$. Potassium cyanide haemolysates were prepared for the separation of the haemoglobins by the IEF technique. ${ }^{2}$ Cord blood from four normal babies was also incubated with $100 \mathrm{mmol} / \mathrm{l}$ $(1.8 \mathrm{~g} / 100 \mathrm{ml})$ glucose at $37 \mathrm{C}$ for 2 hours. The bands representing $\mathrm{HbF}$, $\mathrm{HbA}, \mathrm{HbA}_{1} \mathrm{c}$, and glycosylated fetal haemoglobin $\left(\mathrm{HbF}_{1}\right)$ were excised from the electrophoretic gels and eluted for measurement with a spectrophotometer.

On IEF separation of the cord blood from non-diabetic mothers, three discrete bands could be seen: HbF (mean SD) $67 \cdot 1.8 \cdot 1 \%$; $\mathrm{HbA}$ $23.0 \div 6.2 \%$; and $\mathrm{HbF}_{1} 7.8 \div 1.5 \%$, previously reported to be acetylated fetal haemoglobin. ${ }^{3}$ The values for the babies of diabetic mothers were similar: $\mathrm{HbF} 63.0=9.4 \%$; $\mathrm{HbA} 18.4 \div 3.9 \%$; $\mathrm{HbF}_{1} 8.6 \div 1.9 \%$; as were the maternal $\mathrm{HbA}_{1}$. values from the non-diabetic and diabetic mothers $\left(7.8+1.9 \%\right.$ and $8.0 .2 .0 \%$ respectively). No $\mathrm{HbA}_{1 \mathrm{c}}$ could be observed, either visually or photometrically, in any cord-blood sample. When the cord blood was incubated with excess glucose, the amount of $\mathrm{HbF}_{1}$ increased nearly twofold from $7 \cdot 2+1 \cdot 1$ to $13 \cdot 9-2 \cdot 3 \%$, with a corresponding decrease $\left(68 \cdot 2+4 \cdot 1\right.$ to $57 \cdot 0 \cdot 3 \cdot 7 \%$ ) of $\mathrm{HbF}$ (see figure). The fetal $\mathrm{HbF}_{1}$ of all cordblood samples correlated with the simultaneous maternal $\mathrm{HbA}_{1 \mathrm{c}}$ (Spearman rank correlation $\left.r_{s}=0.4, p<0.05, n=24\right)$. No correlation was observed between fetal $\mathrm{HbF}_{1}$ or maternal $\mathrm{HbA}_{1 \mathrm{c}}$ and birth weight or percentile birth weight (corrected for gestational age, fetal sex, and maternal parity ${ }^{4}$ ).

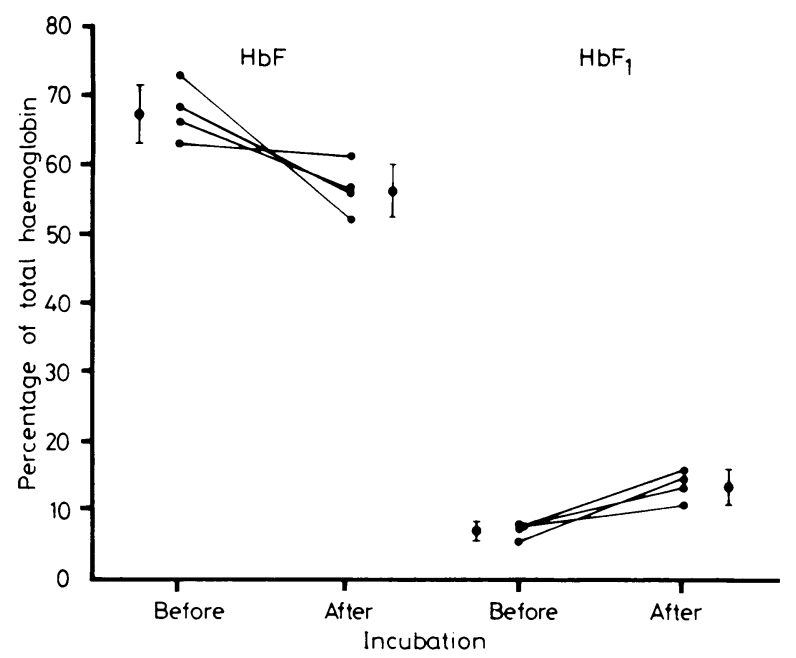

In-vitro incubation of four cord blood samples at $37^{\circ} \mathrm{C}$ with $100 \mathrm{mmol} / 1(1.8 \mathrm{~g} / 100 \mathrm{ml}) \mathrm{D}$-glucose, showing a decrease in $\mathrm{HbF}$ and a simultaneous increase in $\mathrm{HbF}_{1}$. Results of each case are shown together with the mean $\because \mathrm{SD}$ for each group.

\section{Comment}

There is relatively little $\mathrm{HbA}$ in cord blood, and its glycosylated form, $\mathrm{HbA}_{1 \mathrm{c}}$, cannot be detected using the IEF technique. Since the major fraction of haemoglobin present in the newborn is $\mathrm{HbF}$, and as glucose crosses the placenta freely by facilitated diffusion, it is possible that HbF may be "glycosylated" non-enzymatically to form $\mathrm{HbF}_{1}$ in a similar manner to the formation of $\mathrm{HbA}_{1 \mathrm{c}}$ in adults. Indeed, the in-vitro glucose incubation data and the correlation between $\mathrm{HbA}_{1 \mathrm{c}}$ and $\mathrm{HbF}_{1}$ suggest this. Furthermore, it has recently been shown ${ }^{5}$ that non-diabetic alcoholics have raised $\mathrm{HbA}_{1}$ concentrations and that acetaldehyde, produced from ethanol metabolism, also reacts with the $\mathrm{N}$-terminus of the haemoglobin $\beta$-chain. Hence $\mathrm{HbF}_{1}$ may be a combination of the acetylated and glycosylated moieties of $\mathrm{HbF}$. Stepwise-elution chromatography and chemical methods-for example, Flückiger's method-cannot distinguish between fetal and adult haemoglobins, though they may reflect overall glycosylation. $\mathrm{HbF}_{1}$ measured in cord blood by the IEF technique could be used as an index of fetal exposure to glucose during the last few weeks of pregnancy.

This investigation was funded by the Wellcome Trust. We wish to thank Mrs C Whittle for analysing the haemoglobin samples.

Addendum.- Since submission of this paper, Fadel et al (Am $\mathcal{F}$ Obstet Gynecol $1981 ; 139: 397)$ have reported similar results.

${ }^{1}$ Stubbs SM, Leslie RDG, John PN. Fetal macrosomia and maternal diabetic control in pregnancy. Br Med f $1981 ; 282: 439-40$.

2 Jeppsson J-O, Franzen B, Nilsson KO. Determination of the glycosylated haemoglobin fraction $\mathrm{HbA}_{1 \mathrm{c}}$ in diabetes mellitus by thin layer electro focussing. Science Tools 1978;25 (4):69-72.

${ }^{3}$ Schroeder WA, Cua JT, Genji M, Fenniger W. Haemoglobin $F_{1}$, an acetyl-containing haemoglobin. Biochim Biophys Acta 1962;63:532-4.

4 Thomson AM, Billewicz WZ, Hytten FE. The assessment of fetal growth. Br F Obstet Gynaecol 1968;75:903-16.

${ }^{5}$ Stevens VJ, Fantl WJ, Newman CB, Sims RV, Cerami A, Peterson C. Acetaldehyde adducts with haemoglobin. $\mathcal{F}$ Clin Invest $1981 ; 67: 361-9$.

(Accepted 18 May 1981)

Diabetes Research Laboratories, Radcliffe Infirmary, Oxford OX2 6HE

P POON, BSC, ARCS, research biochemist

R C TURNER, MD, clinical reader

Nuffield Department of Obstetrics and Gynaecology, John Radcliffe Hospital, Oxford OX3 9DU

M D G GILLMER, MD, clinical reader

\section{Arthritis of the subtalar joint due to Mycobacterium fortuitum}

Mycobacterium fortuitum is known to cause infection ${ }^{1}$ of the soft tissues but has rarely been implicated in joint infections. ${ }^{2}$ We report a case of subtalar joint infection in which $M$ fortuitum was repeatedly isolated from pus and curettings.

\section{Case report}

A 62-year-old Indian woman strained her right ankle in 1974. Pain and swelling persisted and three years later she had an operation in India for removal of osteophytes. After the operation radiography showed subtalar osteoarthrosis. Three months after the operation she was in England and presented with continuing pain, wasted right peroneal muscles, and a stiff subtalar joint. Ten days later she developed a discharging sinus in the operation scar; radiography showed osteoporosis around the subtalar and ankle joints with partial erosion of the head of the talus. Culture of the pus yielded no growth, and she was given ampicillin and flucloxacillin. One month later there was also erosion of the midtarsal joint and the sinus was curetted. $M$ fortuitum was isolated, resistant to rifampicin, ethionamide, aminosalicylic acid, isoniazid, streptomycin, ethambutol, thiacetazone, capreomycin, and pyrazinamide. She was given isoniazid and rifampicin for one year with ethambutol for the first two months because in-vitro resistance patterns do not necessarily reflect the in-vivo response.

The disease progressed and three new sinuses appeared on the sole of her foot, $M$ fortuitum being isolated from the pus. Biopsy specimens of the sinuses showed multiple non-caseating giant-cell granulomas. Three months later the discharge became more copious: $M$ fortuitum was again grown, and 
Pseudomonas aeruginosa was repeatedly isolated. The $P$ aeruginosa was treated with a 10-day course of gentamicin. Radical curettage of the subtalar joint was performed and during the next year the discharge stopped and radiography showed diminution of cavity size with ankylosis. She subsequently walked well.

Intradermal skin tests for $M$ fortuitum were performed using ranin 1,2 , and 4 and chelonin, which are antigens specific for $M$ fortuitum serotypes 1,2 , and 4 and $M$ chelonei respectively. A $0.1 \mathrm{ml}$ volume of each was injected, and after 72 hours she had areas of induration $6 \mathrm{~mm}$ in diameter at the site of the serotype 4 injection but less than $3 \mathrm{~mm}$ at the $M$ chelonei site, and no response at the other two sites. Induration of $5 \mathrm{~mm}$ or more is considered to be positive.

\section{Comment}

$M$ fortuitum is the commonest of the Runyon group IV rapidly growing mycobacteria. It may cause pulmonary, lymph-gland, softtissue, corneal, heart-valve, and prostatic infections. ${ }^{1}$ In bone vertebral abscesses, medial sternotomy infections, and osteomyelitis of a phalanx after a scraping and of a calcaneum after a puncture wound have been reported. Ohry $e t a l^{3}$ described a case in which $M$ fortuitum osteomyelitis occurred after major trauma with open fractures. Wegmann et $a l^{2}$ reported the case of a woman who had suffered from peritoneal and cervical tuberculosis, poliomyelitis, hepatitis, and ankylosing spondylitis: she had received several cortisone injections to her right shoulder over some years. She presented with $M$ fortuitum arthritis in her right shoulder and ankle.

Antibiotic resistance is always a problem with $M$ fortuitum. The standard drugs for $M$ tuberculosis are rarely useful. Ethionamide, capreomycin, cycloserine, and the aminoglycosides ${ }^{4}$ may occasionally be useful. In our case there was borderline sensitivity to cycloserine and also to kanamycin, so possibly the gentamicin, given for pseudomonas infection, may have helped to eliminate the $M$ fortuitum. In a review of published reports Halpern and $\mathrm{Nagel}^{5}$ concluded that incision and debridement are the mainstay of effective treatment. We assume that the infection in our case was due to contamination of an arthritic joint at the time of the first operation.

We thank Dr P A Jenkins, Mycobacterium Reference Unit, Cardiff, for identifying the organism and sensitivity testing, and Dr J L Stanford, Middlesex Hospital, who supplied the intradermal antigens.

1 Wolinsky E. Nontuberculous mycobacteria and associated diseases. $\mathrm{Am}$ Rev Respir Dis 1979;119:107-159.

2 Wegmann T, Jutz P, Pagon S. Atypische Mykobakteriose, hervorgerufen durch Mycobacterium fortuitum. Schweiz Med Wochenschr 1978;108 684-6.

${ }^{3}$ Ohry A, Brooks M, Steinbach T, Rozin R. Osteomyelitis caused by Mycobacterium fortuitum. Infection $1977 ; 5: 46-8$.

- Nicholson DP, Savier WR. Mycobacterium fortuitum as a pathogen. A case report. Am Rev Respir Dis 1971 ;104:747-50.

5 Halpern AA, Nagel DA. Mycobacterium fortuitum infections: a review with two illustrative cases. Clin Orthop 1978;136:247-52.

(Accepted 20 May 1981)

\section{Whipps Cross Hospital, London E11 1NR}

G B COLVER, MRCP, registrar in chest medicine

B CHATTOPADHYAY, MRCPATH, DCP, director, consultant microbiologist R S FRANCIS, MD, FRCP, consultant chest physician

K M N KUNZRU, FRCS, consultant orthopaedic surgeon

\section{Prostacyclin infusion in haemolytic-uraemic syndrome of children}

Pathological intravascular platelet aggregation plays a major role in the pathogenesis of the microangiopathy of the haemolytic-uraemic syndrome and thrombotic thrombocytopenic purpura. Deficiency of endogenous prostacyclin $\left(\mathrm{PGI}_{2}\right)$, a potent inhibitor of platelet aggregation, has been shown in both conditions, ${ }^{12}$ and this could favour the formation of platelet thrombi in the microcirculation. $\mathrm{PGI}_{2}$ replacement seems a logical therapeutic manoeuvre, but results in adults have been variable. ${ }^{1-3}$ We report our experience with $\mathrm{PGI}_{2}$ infusion in three children with the haemolytic-uraemic syndrome.

\section{Case reports}

Case 1-An 18-month-old girl was admitted after a diarrhoeal illness. On admission the blood pressure was $90 / 50 \mathrm{~mm} \mathrm{Hg}$, she was oliguric $(20 \mathrm{ml} /$ day), serum creatinine concentration was $400 \mu \mathrm{mol} / 1(4.52 \mathrm{mg} / 100 \mathrm{ml})$, platelet count was $25 \times 10^{9} / 1$, serum concentration of fibrin degradation products (FDP) was $80 \mathrm{mg} / \mathrm{l}$, and burr cells were present on the periphera blood film. Peritoneal dialysis was carried out for seven days. On the sixth day in hospital PGI $\mathrm{P}_{2}$ infusion was started at an initial dose of $2.5 \mathrm{ng} / \mathrm{kg} / \mathrm{min}$ and increased to $30 \mathrm{ng} / \mathrm{kg} / \mathrm{min}$ within nine days. The total duration of the infusion was 12 days. Diuresis started on the 15th day in hospital, with progressive improvement in renal function. The platelet count rose to $150 \times 10^{9} / 1$ by the 14 th day and the serum FDP concentration fell to normal by the 19 th day. Five weeks after admission both blood pressure and renal function were normal.

Case 2-A 2-year-old girl was admitted after a diarrhoeal illness. On admission the blood pressure was $120 / 70 \mathrm{~mm} \mathrm{Hg}$, she was anuric, serum creatinine concentration was $520 \mu \mathrm{mol} / 1(5.87 \mathrm{mg} / 100 \mathrm{ml})$, platelet count was $120 \times 10^{9} / 1$, serum FDP concentration was $160 \mathrm{mg} / \mathrm{l}$, and burr cells were present on the peripheral blood film. Peritoneal dialysis was carried out for 10 days. On the fourth day in hospital $\mathrm{PGI}_{2}$ infusion was started at an initial dose of $2.5 \mathrm{ng} / \mathrm{kg} / \mathrm{min}$, increasing to $40 \mathrm{ng} / \mathrm{kg} / \mathrm{min}$ within seven days. The total duration of the infusion was 10.5 days. Diuresis began on the 14 th day with progressive improvement in renal function. The platelet count rose to $300 \times 10^{9} / 1$ and the serum FDP concentration fell to normal by the 16 th day. Ten weeks after admission the blood pressure was normal and the ${ }^{51} \mathrm{Cr}$-EDTA clearance was $69 \mathrm{ml} / \mathrm{min} / 1.73 \mathrm{~m}^{2}$.

Case 3-A 5-year-old girl was admitted after a diarrhoeal illness. On admission the blood pressure was $125 / 85 \mathrm{~mm} \mathrm{Hg}$, she was oliguric $(10 \mathrm{ml}$ day), serum creatinine concentration was $540 \mu \mathrm{mol} / \mathrm{l}(6 \cdot 1 \mathrm{mg} / \mathrm{dl})$, platelet count was $25 \times 10^{9} / 1$, serum FDP concentration was $20 \mathrm{mg} / \mathrm{l}$, and burr cells were present on peripheral blood film. Peritoneal dialysis was carried out for seven days. On the second day in hospital $\mathrm{PGI}_{2}$ infusion was started at an initial dose of $2.5 \mathrm{ng} / \mathrm{kg} / \mathrm{min}$, increasing to $55 \mathrm{ng} / \mathrm{kg} / \mathrm{min}$ within 12 hours. The total duration of the infusion was eight days. Diuresis began on the seventh day in hospital, with progressive improvement in renal function. The platelet count rose to $250 \times 10^{9} / 1$ on the ninth day and the serum FDP concentration fell to normal on the 12th day. Four weeks after admission the blood pressure was normal and the ${ }^{51} \mathrm{Cr}-E D T A$ clearance was $58 \mathrm{ml} / \mathrm{min} /$ $1 \cdot 73 \mathrm{~m}^{2}$.

\section{Comment}

Activity of the prostacyclin was verified by testing the ability of aliquots of the solution to inhibit aggregation of normal platelets induced by adenosine diphosphate. The infusions were delivered via a central venous catheter, no antiplatelet agents were used, and no antihypertensive agents were required during treatment. Side effects were minimal and controllable. One patient developed intermittent drowsiness and vomiting; hypotension and bradycardia occurred only at a dose of more than $50 \mathrm{ng} / \mathrm{kg} / \mathrm{min}$ and rapidly resolved after reduction in the rate of the infusion. The dose range $(30-50 \mathrm{ng} / \mathrm{kg} /$ min) was appreciably greater than the maximum dose tolerated by adult patients with the haemolytic-uraemic syndrome $(6 \mathrm{ng} / \mathrm{kg} / \mathrm{min})^{1}$ and thrombotic thrombocytopenic purpura $(16 \mathrm{ng} / \mathrm{kg} / \mathrm{min}){ }^{2}$

Although these data are preliminary, they show the safety of this treatment in association with frequent blood-pressure monitoring. It is not possible to draw any conclusions on its success; the short oliguric phase in the last case, however, may have been related to the early introduction of the infusion at high dose. We feel sufficiently encouraged at this stage to continue with further evaluation of this treatment. Further experience is, however, essential, preferably on a controlled basis, before any recommendations on its use can be made.

Prostacyclin was synthesised by the Upjohn Company, formulated by the Wellcome Foundation, and kindly supplied by Dr J O'Grady.

1 Webster J, Rees AJ, Lewis PJ, Hensby CN. Prostacyclin deficiency in haemolytic uraemic syndrome. Br Med f 1980;281:271.

2 Hensby CN, Lewis PJ, Hilgard P, et al. Prostacyclin deficiency in thrombotic thrombocytopenic purpura. Lancet 1979;ii:748.

${ }^{3}$ Budd GT, Bukowski RM, Lucas FV, et al. Prostacyclin therapy of thrombotic thrombocytopenic purpura. Lancet 1980;ii:915.

(Accepted 27 May 1981)

Renal Unit and Department of Haematology, Royal Hospital for Sick Children, Yorkhill, Glasgow G3 8SJ

T J BEATTIE, MB, MRCP, registrar in paediatrics (present appointment: senior registrar in paediatrics, Royal Manchester Children's Hospital, Pendelbury, Manchester M27 1HA)

A V MURPHY, MB, FRCP, consultant paediatric nephrologist

M L N WILLOUGHBY, MD, FRCPATH, consultant haematologist

Department of Medicine, Royal Infirmary, Glasgow G4 OSF

J J F BELCH, MB, MRCP, honorary registrar 